\title{
Multiparametric MRI Versus SelectMDx Accuracy in the Diagnosis of Clinically Significant PCa in Men Enrolled in Active Surveillance
}

\author{
PIETRO PEPE, GIUSEPPE DIBENEDETTO, LUDOVICA PEPE and MICHELE PENNISI
}

\author{
Urology Unit, Cannizzaro Hospital, Catania, Italy
}

\begin{abstract}
Background/Aim: To evaluate the diagnostic accuracy of the urinary SelectMDx test in the diagnosis of clinically significant prostate cancer (csPCa) in men enrolled in an active surveillance (AS) protocol. Patients and Methods: From July 2015 to July 2018, 125 men with very low-risk PCa were enrolled in the AS protocol; all patients underwent confirmatory transperineal saturation biopsy $(S P B x)$. In the presence of PI-RADS score $\geq 3$, a targeted MRI/TRUS fusion-guided biopsy was added to SPBx. Postdigital rectal examination urine was collected in 45/125 (36\%) patients before SPBx; the genetic urine analysis was performed using a biomarker-based risk score model, the SelectMDx, that measured mRNA levels of distal-less homeobox 1 (DLX1) and homeobox C6 (HOXC6). Results: A total of 9/45 (20\%) patients were reclassified as csPCa (7 cases $=$ Grade Group 2; 2 cases=Grade Group 3); sensitivity, specificity, positive predictive value, negative predictive value and diagnostic accuracy of mpMRI vs. SelectMDx in the diagnosis of csPCa were equal to $66.6 \mathrm{vs} .55 .6 \%, 87.7$ vs. $65.8 \%, 54.5$ vs. $27.8 \%, 92.3$ vs. $87 \%, 84.9$ vs. $70.3 \%$, respectively. Conclusion: SPBx combined with MRI/TRUS fusion biopsy significantly outperformed the diagnostic accuracy of SelectMDx (70.3\%) in the diagnosis of csPCa in men enrolled in $A S$.
\end{abstract}

Prostate cancer (PCa) is the second commonest tumor among men; PSA screening has been shown to reduce PCa mortality but, at the same time, it is known to lead to unnecessary prostate biopsies and overdiagnosis/overtreatment of indolent PCa (1). Therefore, the necessity to select candidate patients

This article is freely accessible online.

Correspondence to: Pietro Pepe, MD, Urology Unit, Cannizzaro Hospital, Via Messina 829, Catania, Italy. Tel: + 39957263285 , Fax: + 39 957263259, e-mail: piepepe@hotmail.com

Key Words: Prostate cancer, MRI, SelectMDx, active surveillance. for prostate biopsy using more clinical parameters (i.e., risk calculator, prostate health index, 4Kscore, diagnostic imaging) to better separate men at risk for clinically significant prostate cancer (csPCa) (2-5), exists in clinical routine practice. In this respect, multiparametric magnetic resonance image (mpMRI) and novel urine-based molecolar tests that combine mRNA biomarkers with clinical factors have improved the diagnosis for csPCA (6). Urine is a promising source for the development of new biomarkers because after digital rectal examination, it is enriched with DNA, RNA and proteins correlated with PCa. The urinary prostate cancer antigen 3 test (PCA3) was the first Food and Drug Administration-approved RNA-based urinary marker (7-9); recently, the SelectMDx test based on messager RNA detection of DLX1 and HOXC6 in urine, after prostate massage, has been introduced in clinical practice to detect high-risk PCa (10-14). At the same time, novel biomarkers combined with mpMRI can help towards a better selection of patients who are candidates to Active Surveillance (AS) reducing the risk of undergrading; in fact, AS is an alternative to initial definitive treatment of low-risk PCa. Current criteria for selection and follow-up incorrectly exclude some patients eligible for AS and misclassify others who actually harbour significant disease; better prediction of cancer behaviour at diagnosis would allow less strict monitoring and may improve acceptance of AS (15-17). Nomograms, or risk calculators, have the advantage of incorporating easy to retrieve clinical variables such as age, family history, DRE, PSA density, mpMRI and biomarkers. In this study, the diagnostic accuracy of the urinary SelectMDx test in the evaluation of men enrolled in an AS protocol has been prospectively evaluated.

\section{Patients and Methods}

From July 2015 to July 2018, a prospective study was conducted on 125 consecutive men aged between 60 and 73 years (median age: 66 years) with very low-risk PCa enrolled in an AS protocol. The presence of the following criteria defined eligibility: life expectancy greater than 10 years, clinical stage T1c, prostate-specific antigen 
(PSA) below $10 \mathrm{ng} / \mathrm{ml}$, prostate specific antigen density (PSAD) less than $0.20 \mathrm{ng} / \mathrm{ml}$, two or fewer unilateral positive biopsy cores, Gleason score (GS) equal to 6 (ISUP Grade Group 1) and greatest percentage of cancer $(\mathrm{GPC}) \leq 50 \%(17,18)$. The study was approved by the local ethics committee and informed written consent was obtained from each man before enrolment. Six months after PCa diagnosis, all patients underwent digital rectal examination, total PSA, PSAD, 3.0 T pelvic mpMRI and confirmatory transperineal saturation biopsy (SPBx: 30 cores; 24 in the periphery and six in the anterior zone). The procedure was performed with the use of a GE Logiq P6 ecograph (General Electric, Milwaukee, WI, USA) supplied with a biplanar transrectal probe (5-7.5 MHz) using a trucut 18 gauge needle (Bard, Covington, GA, USA) under sedation and antibiotic prophylaxis (19). All mpMRI examinations were performed using a $3.0 \mathrm{~T}$ scanner (ACHIEVA 3T; Philips Healthcare, Best, The Netherlands) equipped with a surface 16 channel phased-array coil placed around the pelvic area with the patient in the supine position. Multiplanar turbo spin-echo T2weighted imaging, axial diffusion-weighted imaging, axial dynamic contrast-enhanced imaging were performed for each patient. mpMRI lesions characterized by a Prostate Imaging Reporting and Data System (PI-RADS) score $\geq 3$ were considered suspicious for cancer; two radiologists blinded to pre-imaging clinical parameters evaluated the MRI data separately and independently. In the presence of mpMRI lesions suggestive of cancer, targeted MRI/TRUS fusion guided biopsies were added to SPBx using a Hitachi 70 Arietta ecograph (Chiba, Japan) supplied with a transrectal biplanar probe. All mpMRI procedures were performed 1 week before prostate biopsy by a radiologist experienced in the field of MRI in PCa. Post-digital rectal examination urine was collected in 45/125 (36\%) patients before SPBx; the genetic urine analysis was performed using a commercially available biomarkerbases risk score model SelectMDx (MDx Health, Irvine, CA, USA) (10-14). The test measured mRNA levels of distal-less homeobox 1 (DLX1) and homeobox C6 (HOXC6) in a post-DRE urine specimen and combines these with serum PSA, PSA density, DRE status, age, and family history of PCa. Finally, the diagnostic accuracy in the diagnosis of csPCa of SelectMDx was compared with mpMRI results.

\section{Results}

Nine out 45 (20\%) patients submitted to repeat SPBx were reclassified (Table I) based on upgraded Grade Group (7 cases had GS 3+4/Grade Group 2 and 2 cases had GS $4+3$ /Grade Group 3); in addition, the median number of positive cores was 5 (range $=3-8$ ) and median GPC was equal to $70 \%$ (range $=40-100 \%$ ). In detail, csPCa were located only in the anterior $v s$. the periphery zone of the gland in $3 / 9$ (33.3\%) vs. 6/9 (66.7\%) cases, respectively.

Of the remaining $36(80 \%)$ patients, 29 were found to have very low-risk PCa and in 7 cancer was absent. Multiparametric MRI and SelectMDx results are listed in Table I; in the presence of csPCa, mpMRI demonstrated a PI-RADS score of 3 and 4 in 4/9 (44.4\%) and in 2/9 (22.2\%) patients, and median SelectMDX value was $26 \%$ (range $=12$ $40 \%$ ). In one case of csPCa, only SelectMDx resulted abnormal, on the contrary, in three cases only mpMRI was suspicious. No one suffered significant complication from prostate biopsy requiring admission to Hospital.

Sensitivity, specificity, positive predictive value (PPV), negative predictive value (NPV) and diagnostic accuracy of mpMRI vs. SelectMDx in the diagnosis of csPCa were equal to $66.6 v s .55 .6 \%, 87.7 v s .65 .8 \%, 54.5 v s .27 .8 \%, 92.3 v s$. $87 \%, 84.9$ vs. $70.3 \%$, respectively.

\section{Discussion}

Recent advances in genomic sequencing and molecular classification led to development of a plethora of assays for PCa diagnosis; therefore, considerable effort has been given to identify novel tissue, serum, and urine-based biomarkers to better stratify at-risk patients $(20,21)$. For the diagnosis of PCa, biomarkers should ideally be detectable in body fluids that can be obtained non-invasively and therefore urine has emerged as the substrate for the non-invasive detection of PCa. The first fully translated RNA-based molecular diagnostic test for the detection of prostate cancer in urine was the PCA3 test (9); although, the combined use of the Progensa PCA3 test and TMPRSS2-ERG could significantly improve the sensitivity for prostate cancer diagnosis $(22,23)$, the value of this combination for predicting biopsy csPCa in urine is controversial (24). A novel urinary assay-based risk score called SelectMDx combines serum PSA, PSAD and clinical factors such as age and prior negative biopsy with two mRNA signatures: urinary homeobox C6 and distal-less homeobox 1 (10-14). The test measures the amount of two genes that are associated with aggressive prostate cancer with a high NPV for Grade Group $\geq 2$ (Gleason score $\geq 7$ ). In definitive, SelectMDx combined with mpMRI could better select men candidates to AS ruling out patients who do not have csPCa improving the cost-effectiveness (25-27). In a multicenter study including 916 men submitted to initial prostate biopsy, Haese et al. (28) reported a sensitivity, specificity and NPV of SelectMDx in the diagnosis of csPCa equal to 93,47 and $95 \%$, respectively.

In our series, 9/45 (20\%) patients were reclassified based on upgraded Grade Group $(7$ cases $=$ GS $3+4 ; 2$ cases $=\mathrm{GS}$ $4+3)$. Multiparametric MRI and SelectMDx missed 3/9 (33.3\%) and 4/9 (44.5\%) csPCa respectively; moreover, mpMRI combined with SelectMDx diagnosed 7/9 (77.8\%) csPCa. SPBx combined with MRI/TRUS fusion biopsy outperformed significantly the diagnostic accuracy of mpMRI $(84.5 \%)$ and SelectMDx $(70.3 \%)$ in the diagnosis of csPCa. Therefore, SelectMDx should be considered as one piece of the puzzle assisting the physicians and patients in the re-evaluation of men enrolled in AS protocols (29) in order to select for upgrading men at risk in need of early repeat prostate biopsy; mpMRI improves prostate biopsy strategies to detect csPCa (30), but still today, systematic prostate biopsy should be anyway performed (31). 
Pepe et al: mpMRI vs. SelectMDx in Diagnosing Clinically Significant PCa

Table I. Multiparametric magnetic resonance imaging (mpMRI), PSA and SelectMDx findings in 9/45 men re-classified at confirmatory prostate biopsy.

\begin{tabular}{|c|c|c|c|}
\hline Number of patients & $\begin{array}{c}\text { mpMRI } \\
\text { PI-RADS score } \leq 2\end{array}$ & $\begin{array}{c}\text { mpMRI } \\
\text { PI-RADS score } \geq 3\end{array}$ & $\begin{array}{l}\text { SelectMDx } \\
\text { test suspicious* }\end{array}$ \\
\hline 45 (overall) & $34(75.6 \%)$ & $11(24.4 \%)$ & $18(40 \%)$ \\
\hline Indolent PCa/normal parenchyma 36/45 (80\%) & 31 & 5 & 14 \\
\hline $\operatorname{csPCa} 9 / 45(20 \%)$ & 3 & 6 & 5 \\
\hline False positive for csPCa & 0 & 5 & 14 \\
\hline False negative for csPCa & 3 & 0 & 4 \\
\hline
\end{tabular}

csPCa: Clinically significant prostate cancer; PI-RADS: Prostate Imaging Reporting and Data System; *SelectMDX value: estimated risk for $\operatorname{csPCa}=26 \%($ range $=12-40 \%)$.

Regarding our results, some considerations should be adressed. Firstly, the results were evaluated on biopsy specimens and not on the entire prostate gland or performing a template mapping biopsy. Secondly, the diagnostic accuracy of SelectMDx equal to $70.3 \%$ in diagnosing csPCa has been obtained in patients AS with very low-risk PCa but it might improve in case of initial or repeat prostate biopsy. Finally, a greater number of patients should be evaluated.

In conclusion, SPBx combined with MRI/TRUS fusion biopsy significantly outperformed the diagnostic accuracy of SelectMDx (70.3\%) in the diagnosis of csPCa in men enrolled in an AS protocol.

\section{Conflicts of Interest}

The Authors declare that no conflicts of interest exist in regard to this study.

\section{Authors' Contributions}

The Authors equally contributed to the design and implementation of the research, to the analysis of the results and to the writing of the manuscript.

\section{References}

1 Roobol MJ and Carlsson SV: Risk stratification in prostate cancer screening. Nature Rev Uro 10: 38-48, 2013. PMID: 30928162. DOI: 10.1016/j.eururo.2019.03.010

2 Truong M, Baack Kukreja JE, Rais-Bahrami S, Barashi NS, Wang B, Nuffer Z, Park JH, Lam K, Frye TP, Nix JW, Thomas JV, Feng C, Chapin BF, Davis JW, Hollenberg G, Oto A, Eggener SE, Joseph JV, Weinberg E and Messing EM: Multiinstitutional Clinical Tool for Predicting High-risk Lesions on 3Tesla Multiparametric Prostate Magnetic Resonance Imaging. Eur Urol Oncol 2: 257-264, 2019. PMID: 31200839. DOI: 10.1016/j.euo.2018.08.008

3 Alberts AR, Roobol MJ, Verbeek JFM, Schoots IG, Chiu PK, Osses DF, Tijsterman JD, Beerlage HP, Mannaerts CK, Schimmöller L, Albers P and Arsov C: Prediction of high-grade prostate cancer following multiparametric magnetic resonance imaging: Improving the Rotterdam European randomized study of screening for prostate cancer risk calculators. Eur Urol 75: 310318, 2019. PMID: 30082150. DOI: 10.1016/j.eururo.2018.07.031

4 Osses DF, Roobol MJ and Schoots IG: Prediction medicine: Biomarkers, risk calculators and magnetic resonance imaging as risk stratification tools in prostate cancer diagnosis. Int $\mathrm{J}$ Mol Sci 20(7) pii: E1637, 2019. PMID: 30986955. DOI: 10.3390/ijms20071637

5 Raja N, Russell CM and George AK: Urinary markers aiding in the detection and risk stratification of prostate cancer. Transl Androl Urol 7(Suppl 4): S436-S442, 2018. PMID: 30363496. DOI: $10.21037 /$ tau.2018.07.01

6 Alford AV, Brito JM, Yadav KK, Yadav SS, Tewari AK and Renzulli J: The use of biomarkers in prostate cancer screening and treatment. Rev Urol 19: 221-234, 2017. PMID: 29472826. DOI: $10.3909 /$ riu0772

7 Govers TM, Caba L and Resnick MJ: Cost-effectiveness of urinary biomarker panel in prostate cancer risk assessment. J Urol 200: 1221-1226, 2018. PMID: 29472826. DOI: 10.1016/ j.juro.2018.07.034

8 Leyten GH, Hessels D, Smit FP, Jannink SA, de Jong H, Melchers WJ, Cornel EB, de Reijke TM, Vergunst H, Kil P, Knipscheer BC, Hulsbergen-van de Kaa CA, Mulders PF, van Oort IM and Schalken JA: Identification of a candidate gene panel for the early diagnosis of prostate cancer. Clin Cancer Res 21: 3061-3070, 2015. PMID: 25788493. DOI: 10.1158/1078-0432.CCR-14-3334

9 Pepe P, Fraggetta F, Galia A, Skonieczny G and Aragona F: PCA3 score and prostate cancer diagnosis at repeated saturation biopsy. Which cut-off: 20 or 35? Int Braz J Urol 38: 489-495, 2012. PMID: 22951161. DOI: 10.1590/s1677-55382012000400008

10 Van Neste L, Hendriks RJ, Dijkstra S, Trooskens G, Cornel EB, Jannink SA, de Jong H, Hessels D, Smit FP, Melchers WJ, Leyten GH, de Reijke TM, Vergunst H, Kil P, Knipscheer BC, Hulsbergenvan de Kaa CA, Mulders PF, van Oort IM, Van Criekinge W and Schalken JA: Detection of high-grade prostate cancer using a urinary molecular biomarker-based risk score. Eur Urol 70: 740748, 2016. PMID: 27108162. DOI: 10.1016/j.eururo.2016.04.012

11 Hamid AR, Hoogland AM, Smit F, Jannink S, van Rijt-van de Westerlo C, Jansen CF, van Leenders GJ, Verhaegh GW and Schalken JA: The role of HOXC6 in prostate cancer development. Prostate 75: 1868-1876, 2015. PMID: 26310814. DOI: $10.1002 /$ pros. 23065 
12 Govers TM, Hessels D, Vlaeminck-Guillem V, Schmitz-Dräger BJ, Stief CG, Martinez-Ballesteros C, Ferro M, BorqueFernando A, Rubio-Briones J, Sedelaar JPM, van Criekinge W and Schalken JA: Cost-effectiveness of SelectMDx for prostate cancer in four European countries: a comparative modeling study. Prostate Cancer Prostatic Dis 22: 101-109, 2019. PMID: 30127462. DOI: 10.1038/s41391-018-0076-3

13 Dijkstra S, Govers TM, Hendriks RJ, Schalken JA, Van Criekinge W, Van Neste L, Grutters JPC, Sedelaar JPM and van Oort IM: Cost-effectiveness of a new urinary biomarker-based risk score compared to standard of care in prostate cancer diagnostics - a decision analytical model. BJU Int 120: 659-665, 2017. PMID: 28370948. DOI:10.1111/bju.13861

14 Fujita $\mathrm{K}$ and Nonomura N: Urinary biomarkers of prostate cancer. Int J Urol 25: 770-779, 2018. PMID: 30129068. DOI: 10.1111/iju.13734

15 Drost FH, Nieboer D, Morgan TM, Carroll PR, Roobol MJ and Movember Foundation's Global Action Plan Prostate Cancer Active Surveillance (GAP) Consortium: Predicting biopsy outcomes during active surveillance for prostate cancer: External validation of the canary prostate active surveillance study risk calculators in five large active surveillance cohorts. Eur Urol 76(5): 693-702, 2019. PMID: 31451332. DOI: 10.1016/j.eururo.2019.07.041

16 Glaser ZA, Gordetsky JB, Porter KK, Varambally S and RaisBahrami S: Prostate cancer imaging and biomarkers guiding safe selection of active surveillance. Front Oncol 7: 256, 2017. PMID: 29164056. DOI: 10.3389/fonc.2017.00256

17 Pepe P, Cimino S, Garufi A, Priolo G, Russo GI, Giardina R, Reale G, Pennisi M and Morgia G: Confirmatory biopsy of men under active surveillance: extended versus saturation versus multiparametric magnetic resonance imaging/transrectal ultrasound fusion prostate biopsy. Scand J Urol 51: 260-263, 2017. PMID: 28513296. DOI: 10.1080/21681805.2017

18 Pepe $\mathrm{P}$ and Pennisi $\mathrm{M}$ : Prostate cancer diagnosis and management across twenty years of clinical practice: A singlecenter experience on 2,500 cases. Anticancer Res 39: 1397-1401, 2019. PMID: 30842174. DOI: 10.21873/anticanres.13254

19 Pepe P, Garufi A, Priolo GD, Galia A, Fraggetta F and Pennisi M: Is it time to perform only MRI targeted biopsy? Ou experience in 1032 men submitted to prostate biopsy. J Urol 200: 774-778, 2018. PMID: 29679618. DOI: 10.1016/j.juro.2018. 04.061

20 Bhat A and Ritch CR: Urinary biomarkers in bladder cancer: where do we stand? Curr Opin Urol 29: 203-209, 2019. PMID: 30855372. DOI: 10.1097/MOU.0000000000000605

21 Kearns JT and Lin DW: Improving the specificity of PSA screening with serum and urine markers. Curr Urol Rep 19(10): 80, 2018. PMID: 30105509. DOI: 10.1007/s11934-018-0828-6

22 Hessels D, Smit FP, Verhaegh GW, Witjes JA, Cornel EB and Schalken JA: Detection of TMPRSS2-ERG fusion transcripts and prostate cancer antigen 3 in urinary sediments may improve diagnosis of prostate cancer. Clin Cancer Res 13: 5103-5108, 2007. PMID: 17785564. DOI: 10.1158/1078-0432.CCR-07-0700
23 Robert G, Jannink S, Smit F, Aalders T, Hessels D, Cremers R, Mulders PF and Schalken JA: Rational basis for the combination of PCA3 and TMPRSS2:ERG gene fusion for prostate cancer diagnosis. Prostate 73: 113-120, 2013. PMID: 22674214. DOI: 10.1002/pros.22546

24 Leyten GH, Hessels D, Jannink SA, Smit FP, de Jong H, Cornel EB, de Reijke TM, Vergunst H, Kil P, Knipscheer BC, van Oort IM, Mulders PF, Hulsbergen-van de Kaa CA and Schalken JA: Prospective multicentre evaluation of PCA3 and TMPRSS2ERG gene fusions as diagnostic and prognostic urinary biomarkers for prostate cancer. Eur Urol 65: 534-542, 2014. PMID: 23201468. DOI: 10.1016/j.eururo.2012.11.014

25 Govers TM, Caba L and Resnick MJ: Cost-effectiveness of urinary biomarker panel in prostate cancer risk assessment. J Urol 200: 1221-1226, 2018. PMID: 30012363. DOI: 10.1016/j.juro.2018.07.034

26 Pepe P, Pepe G, Pepe L, Garufi A, Priolo GD and Pennisi M: Cost-effectiveness of multiparametric MRI in 800 men submitted to repeat prostate biopsy: Results of a public health model. Anticancer Res 38: 2395-2398, 2018. PMID: 29599367. DOI: 10.21873 /anticanres.12489

27 Tan GH, Nason G, Ajib K, Woon DTS, Herrera-Caceres J, Alhunaidi $\mathrm{O}$ and Perlis N: Smarter screening for prostate cancer. World J Urol 37: 991-999, 2019. PMID: 30859272. DOI: 10.1007/s00345-019-02719-5

28 Haese A, Trooskens G, Steyaert S, Hessels D, Brawer M, Vlaeminck-Guillem V, Ruffion A, Tilki D, Schalken J, Groskopf $\mathrm{J}$ and Van Criekinge W: Multicenter optimization and validation of a 2-gene mRNA urine test for detection of clinically significant prostate cancer before initial prostate biopsy. J Urol 202: 256-263, 2019. PMID: 31026217. DOI: 10.1097/JU.0000000000000293

29 Zhao F, Vesprini D, Liu RSC, Olkhov-Mitsel E, Klotz LH, Loblaw A, Liu SK and Bapat B: Combining urinary DNA methylation and cell-free microRNA biomarkers for improved monitoring of prostate cancer patients on active surveillance. Urol Oncol 37(5): 297.e9-297.e17, 2019. PMID: 30777394. DOI: 10.1016/j.urolonc.2019.01.031

30 Pepe P, Garufi A, Priolo G, Candiano G, Pietropaolo F, Pennisi M, Fraggetta F and Aragona F: Prostate cancer detection at repeat biopsy: cand pelvic phased-array multiprametric MRI replace saturation biopsy? Anticancer Res 33(3): 1195-1199, 2013. PMID: 23482802.

31 Pepe P, Garufi A, Priolo G and Pennisi M: Can MRI/TRUS fusion targeted biopsy replace saturation prostate biopsy in the reeevaluation of men in active surveillance? World J Urol 34: 1249-1453, 2016. PMID: 26699628. DOI: 10.1007/s00345-015$1749-3$

Received September 15, 2019

Revised November 2, 2019

Accepted November 4, 2019 